\title{
Adaptation of General Belongingness Scale into Turkish for Adolescents: Validity and Reliability Studies"
}

\author{
Mehmet Ali Yıldız ${ }^{1}$ \\ ${ }^{1}$ Department of Guidance and Psychological Counseling, Adiyaman University, Adiyaman, Turkey \\ Correspondence: Mehmet Ali Yıldız, Adıyaman University, Department of Guidance and Psychological Counseling, \\ Faculty of Education, 02040 Adiyaman, Turkey.
}

Received: December 12, 2016

Accepted: January 13, 2017 Online Published: January 23, 2017

doi:10.11114/jets.v5i2.2060

URL: http://dx.doi.org/10.11114/jets.v5i2.2060

\begin{abstract}
The current research aims to adapt the General Belongingness Scale (GBS), developed by Malone, Pillow, and Osman (2012), into Turkish for adolescents and to conduct the validity and reliability studies for it. Ages of the participants, a total of 567 adolescents including 274 males $(48.3 \%$ ) and 293 females $(51.7 \%)$ ranged between 14 and 18 (average age $=15.76$ ). For the construct validity of GBS, exploratory and confirmatory factor analyses were conducted. Factor analyses results indicated that the scale included two factors as it is in the original form. Factor loadings of the items varied between .55 and .84 . To provide validity of the GBS, Pearson Correlation Coefficents between belongingness and loneliness $(\mathrm{r}=-.64)$, life satisfaction $(\mathrm{r}=.36)$, attachment to parents (varied between $\mathrm{r}=.21$ and $\mathrm{r}=.39)$ and attachment to peers $(\mathrm{r}=.33$ and $\mathrm{r}=.39)$ were computed and they were all significant. Cronbach's alpha coefficient calculated for the scale reliability was .76 for acceptance/inclusion sub-dimension, .85 for rejection/exclusion and .81 for overall scale. Test-retest reliability of the GBS was run with 97 students, and it was found as .80 . The research findings indicated that the GBS was a valid and reliable instrument to assess general belongingness for Turkish adolescents.
\end{abstract}

Keywords: general belongingness, scale adaptation, validity, reliability, adolescence

\section{Introduction}

\subsection{Introduce the Problem}

People have a widespread instinct of belongingness towards creating and preserving permanent, positive and important interpersonal relationships. Two criteria of satisfying this instinct are available. First of all, individuals often need a pleasant emotional interaction with one or a few people. Secondly, during these interactions, individuals need to care about each other's wellbeing, to maintain a mutual long-lasting emotional interest, and these relationships need to be temporally sustainable (Baumeister and Leary, 1995). Anant (1996; as cited in Hagerty, Lynch-Sauer, Patusky, Bouwsema, and Collier, 1992) described the feeling of emotion as an experience of individuals' personal attachment to a system or environment upon perceiving themselves as parts of this system or environment. According to Hagerty et al. (1992), on the other hand, the said system may be a relationship or organization as well as a natural or cultural medium. Within this conceptualization, belongingness is defined on two dimensions. First, it is about valued involvement: experiencing the feelings of being valued, needed, and accepted. The second is about fit: individuals' characteristics and his/her perceptions of the complementariness of the system or environment.

According to Baumeister and Leary (1995), belongingness has two basic features. First, people often need a personal relationship or interaction with another person. Ideally, these interactions are expected to be emotionally positive and to make the individual happier; however, what is important in reality is that these interactions need to be away from conflict and negative emotions. Secondly, people need to expect that their relationships may continue in future and they also need to perceive an emotional interest, an interpersonal bond, and sustainment. In this respect, an individual's interactive relationship with another person is closely linked and the perception of this link is required for feelings of belongingness.

\footnotetext{
*This study was presented at "Istanbul 2013 World Congress of Psychological Counseling and Guidance” in Boğaziçi University.
} 
An evolutionary view reveals that belongingness instinct is in the center of human survival and culture. Individuals' personal characteristics with instincts to provide acceptance by others and to inhibit exclusion are indispensable tools that provide survival and reproduction (Malone, Pillow, and Osman, 2012). The studies conducted showed that belongingness instinct had important effects on cognitive processes and emotional patterns and low levels of attachment were found to be associated with poor adjustment and well-being (Baumeister and Leary, 1995). People as social beings need to feel belonging to their environment, nature, and the society in order to protect their mental health. According to Allen and Bowles (2012), belongingness is an important feature of psychological functionality and it is, at the same time, associated with individuals' well-being. Anant (1966; as cited in Malone et al., 2012), on the other hand, claimed that belongingness was the lost circle in understanding the mental health from the interpersonal perspective. Yildiz (2016) emphasized that low levels of individuals' belongingness or their belongingness needs not satisfied could bring along feelings of loneliness. Baumeister and Tice (1990) stated that excluding individuals in social groups was the most effective factor leading to perceiving themselves as inadequate, guilty, and unattractive and experiencing anxiety. Hagerty and Williams (2010) determined that feeling of belongingness was an important predictor of depression in individuals. Baskin, Wampold, Quintana, and Enright's (2010) study showed that belongingness was importantly effective on low peer acceptance, loneliness, and depression. Their study results showed that belongingness could serve as an important protection against low peer acceptance and loneliness. Mellor Stokes, Firth, Hayashi, and Cummins' (2008) study indicated that people with low feelings of belongingness had low levels of life satisfaction and they enjoyed interpersonal relationships less. They also reported that loneliness mediated between individuals' unsatisfied needs of belonging and the life satisfaction. In a study conducted by Yildız (2016) on adolescents, on the other hand, it was demonstrated that general belongingness was associated with attachment and loneliness and moreover, it determined adolescents' life satisfactions. In another study, O'Rourke and Cooper (2010) found that children's belongingness levels were closely associated with their levels of happiness and optimism.

It is thought that individuals' belongingness levels may affect their social lives and, therefore, mental health. Hence, in another perspective, Baumeister and Leary (1995) stated that lack of belongingness could have various negative effects on individuals and it could lead to a severe deprivation. In addition, they emphasized that a great portion of individuals' behaviors, emotions, and thoughts stemmed from this interpersonal basic instinct. According to Mellor et al. (2008), failure in meeting belongingness needs may lead to social isolation, alienation, and loneliness. Thus, the feeling of belongingness is not only a precursor of social attachment but it also serves as a buffer against loneliness. On the other hand, unsatisfied feelings of belongingness may, at the same time, deteriorate individuals' well-being. Chen (2003) found that the quality of adolescents' relationships with their families contributed to belongingness in the family. Similarly, high quality of peer relations increased adolescents' belongingness to the family and belongingness to peers reduced adolescents' feelings of loneliness. Choenarom, Williams, and Hagerty (2005) reported a direct relationship between depression and belongingness. They emphasized that feelings of belongingness had to be developed in order to reduce depression levels in individuals.

From an evolutionary perspective, Baumeister and Leary (1995) stated that both regular social contact and feelings of attachment were needed as the basic-components of belongingness concept. On the other hand, Hagerty et al. (1992) stated that individual's achieved (owned) belongingness could be covertly influenced by his/her relationships with social groups, beyond interpersonal relationships, and his/her self-structure as well as relationships with animals, nature, and intellectual/spiritual elements. For instance, they stated that an individual may have belongingness towards animals; however, his/her belongingness towards people may be lower. They, therefore, emphasized that referents corresponding to belongingness had to be determined. Based on these ideas, it may be said that an instrument to help evaluate individuals' general belongingness may be needed.

Theoretical explanations and research findings in the relevant literature point out that belongingness level of individuals are associated with their mental health problems as well as critically important for the development and sustainment of mental health. Considering adolescence as a fragile period in one's development with various risks for adolescents' mental health, an instrument is needed in order to determine adolescents' belongingness levels in this period and to be used in prevention and intervention studies on adolescents. It is also thought that the current study will contribute to the relevant literature in Turkey since there are few studies about adolescents' general belongingness levels as well as to the . For this purpose, in the current study, adaptation of the General Belongingness Scale (GBS) developed by Malone et al. (2012) to Turkish was conducted and psychometric characteristics of the scale were examined.

\section{Method}

\subsection{Translation Study for the General Belongingness Scale (GBS)}

In 2012, Prof. David R. Pillow was contacted through email about adapting GBS in to Turkish language and translation of the scale into Turkish was started upon obtaining required permission for adaptation. Translation of the GBS into 
Turkish language was conducted by a total of five professionals including two scholars within the field of Psychological Counseling and Guidance and two teachers of English language and an expert psychological counselor. The GBS application form was finalized upon examination of translation by experts separately.

\subsection{General Belongingness Scale}

General Belongingness Scale (GBS) was developed by Malone et al. (2012) to determine general belongingness levels of adult individuals. The scale is a self-report instrument measuring belongingness levels of individuals through two dimensions as acceptance/inclusion and rejection/exclusion. Malone et al. (2012) developed the GBS in order to evaluate multiple levels of belongingness including close peer relationships, family, and other members of community, beyond interpersonal relationships, based on the relevant literature. Malone et al. (2012), firstly, formed a pool of 30 items considered to measure general belongingness. The scale is answered on a 7-point Likert-type scale ranging from "Strongly Disagree" to "Strongly Agree". Three separate studies were conducted to provide validity and reliability of the scale. Exploratory factor analysis resulted in two dimensions. In addition, a parallel analysis conducted to determine the factor numbers indicated a two-factor structure. EFA resulted in 12 items with factor values ranging between .66 and .92. It was found that these two dimensions explained $68.3 \%$ of the total variance. The results showed that 6 items represented rejection/exclusion and other items formed the acceptance/inclusion subscale. Internal consistency coefficient for the scale was found as $\alpha=.94$. Confirmatory factor analysis (CFA) for the GBS was conducted on total 875 individuals in two groups including 440 and 345 each. Factor loadings in CFA were found to be between 65 and .82 . Fit indices, were as follows: $\mathrm{CFI}=.97$; TLI $=.96$; RMSEA $=.08$; SRMR $=.03$. A negative relationship was found between the General Belongingness Scale and Neuroticism as a sub-dimension of Five-Factor Personality Inventory and a positive relationship between the General Belongingness Scale and Extraversion as a sub-dimension of Five-Factor Personality Inventory.

\subsection{Participants}

Adolescents who attended the Rekabet Kurumu Anatolian High School and Sezai Karakoç Anatolian High School in 2011-2012 academic years in the town of Yenişehir, the city of Diyarbakır participated in the current research The sample included total 567 adolescents between ages 14 and 18 (average age=15.76), with $274(48.3 \%)$ males and 293 $(51.7 \%)$ females. Simple random sampling was used to select the sample.

\subsection{Instruments}

\subsubsection{UCLA Loneliness Scale}

The UCLA Loneliness Scale was developed by Russel, Peplau, and Ferguson (1978) to measure individuals' loneliness levels. The scale was revised by Russel, Peplau, and Cutrona (1980) and, upon reviewing all items, 10 items were made positive and 10 negative. It is a Likert-type scale with scores such as " 1 - I never experience, 2- I rarely experience, 3- I sometimes experience, and 4-I often experience". Adaptation studies for the scale into Turkish language were conducted by Demir (1989). In the validity study by Demir (1989), to determine how well the scale distinguished individuals experiencing feelings of loneliness, UCLA Loneliness Scale was administered on a group of 36 individuals suffering from loneliness with a neurotic depressive diagnosis and a second group of 36 individuals not suffering from loneliness. Obtained test results showed a significant difference of scores on scale between the two groups. For the criterion validity of the scale, correlations on levels of .77 and .82 with scores of Beck Depression Scale and Social Introversion sub-dimension of the Multiscore Depression Scale and UCLA Loneliness Scale were obtained. In the reliability analyses for the scale, a high level of internal consistency coefficient with .94 was found. A correlation level of .94 was found between the scores of two administration of test-retest with a five-week interval. In the current study, the internal consistency coefficient of the scale was found as .87 .

\subsubsection{The Brief Multidimensional Students' Life Satisfaction Scale (BMSLSS)}

The adaptation studies of the BMSLSS, developed by Seligson, Huebner, and Valois (2003) to determine students' life satisfaction, into Turkish language were conducted by Siyez and Kaya (2008). The BMSLSS with totally six items measured both students' general life satisfaction and the life satisfaction that they perceived in five domains such as family, friends, school, self, and neighborhood. Exploratory factor analysis yielded factor loadings between .49 and .82 . Unidimensional structure of the scale explained $48 \%$ of the total variance. Students' total life satisfaction scores were determined by adding the scores obtained on the sub-dimensions of BMSLSS. The internal consistency coefficient calculated for the scale reliability was found as .89 . Test-retest reliability coefficient calculated for the overall scale was found as .82. In the current research, internal consistency of the scale was calculated as .79.

\subsubsection{Inventory of Parent and Peer Attachment (IPPA)}

Inventory of Parent and Peer Attachment (IPPA) was developed by Armsden and Greenberg (1987) to measure adolescents' attachment to parents and peers. The adaptation study of IPPA into Turkish language was conducted by 
Kocayörük (2010). In IPPA, attachment experiences are measured through three sub-dimensions (trust, communication, and alienation) and, individuals' total attachment scores are calculated by adding the scores obtained on these three sub-dimensions. Confirmatory factor analysis conducted for construct validity of IPPA showed the fit indices of the three sub-dimensions as follows: $\mathrm{SRMR}=.05$ and $.07, \mathrm{RMSEA}=.06$ and $.07, \mathrm{GFI}=.89$ and .91 , AGFI $=.86$ and .89 , and $\mathrm{CFI}=.93$ and .94 . The internal consistency coefficients calculated for the scale reliability were found between .89 and .92. In the current research, the internal consistency coefficient for attachment to mother sub-dimension was determined as .92; the internal consistency coefficient for attachment to father sub-dimension was determined as .92, and the internal consistency coefficient for attachment to peer sub-dimension was determined as .91.

\subsubsection{Personal Information Form}

Personal Information Form was prepared in order to determine the age, gender, and grade levels of adolescent participants.

\subsection{Data Analysis}

Exploratory and confirmatory factor analyses were conducted in order to determine the construct validity of General Belongingness Scale. For the criterion validity of the GBS, Inventory of Parent and Peer Attachment, The Brief Multidimensional Students' Life Satisfaction Scale, and the UCLA Loneliness Scale were used. For the scale reliability, test-retest values, internal consistency Cronbach's Alpha values, Average variance extracted (AVE), and Composite reliability (CR) values were calculated. SPSS 17.0, LISREL 8.51, and Monte Carlo PCA Parallel Analysis software were used.

\section{Results}

\subsection{Findings associated with GBS Validity}

\subsubsection{Exploratory Factor Analysis (EFA) Results}

Firstly, exploratory factor analysis was conducted in order to determine the construct validity of the scale. In EFA, first of all, a direct oblimin oblique rotation technique is recommended when the subscales are assumed to be correlated (Pallant, 2011). Thus, direct oblimin oblique rotation technique was used; however, due to low-level relationship among the factors $(r=.21)$, varimax orthogonal rotation technique was used (Tabachnick and Fidell, 2013). Factors with Eigenvalue values above 1 were taken as bases in the analyses (Brown, 2006; Hair, Black, Babin, and Anderson, 2010; Pallant, 2011; Tabachnick, and Fidell, 2013). Items with .40 factor loading and above were retained (Büyüköztürk, 2008; Şeker and Gençdoğan, 2006). When items were included in more than one factor, at least a difference of .10 factor loading was considered between the values of an item in both factors. Prior to the exploratory factor analysis, Kaiser Meyer-Olkin (KMO) values were found significant with Bartlett Test $\left(\chi^{2}=2145.794, \mathrm{df}=66, p<.001\right)$ (Hair et al., 2010). Minimum KMO value, in order to conduct factor analysis on the research data, is recommended at a level of .60 (Pallant, 2011; Tabachnick and Fidell, 2013; Şeker and Gençdoğan, 2006). Based on that, data can be considered fit for factor analysis.

In order to determine the number of dimensions in the GBS, scree plot graph was examined (Figure 1). Later, parallel analysis technique was used as the final resort to decide about the number of dimensions. As can be seen in Figure 1, two sharp declines are observed on the scree-plot graph. Based on this, has a two-dimensional structure as in the original form. Pallant (2011) states that in studies within education and psychology, parallel analysis must be conducted and the results must be reported. Table 1 includes Eigenvalues obtained from parallel analysis of the GBS and Eigenvalues of exploratory factor analysis.

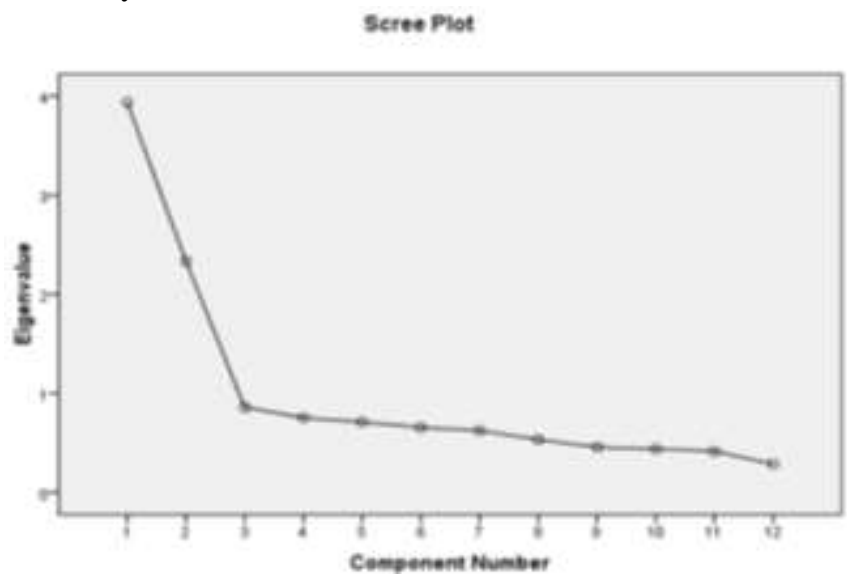

Figure 1. Scree plot graphic for the GBS 
Table 1. Eigenvalue comparison of exploratory factor analysis and parallel analysis

\begin{tabular}{llll}
\hline & $\begin{array}{l}\text { Eigenvalue results of } \\
\text { EFA }\end{array}$ & $\begin{array}{l}\text { Eigenvalue results of } \\
\text { parallel analysis criteria }\end{array}$ & Decision \\
\hline Dimension I & 3.94 & 1.24 & Accepted \\
Dimension II & 2.33 & 1.18 & Accepted \\
Dimension III & .86 & 1.13 & Rejected \\
\hline
\end{tabular}

The comparison of Eigenvalues obtained through the exploratory factor analysis on the GBS and the random values obtained through parallel analysis showed that Eigenvalues obtained for the first and second dimensions were higher than the values obtained through parallel analysis; however, for the third dimension, the values obtained through the parallel analysis were higher than those obtained through EFA. Thus, the GBS was found to have a two-dimensional structure as in the original form.

As can be seen in Table 2, EFA results showed that General Belongingness Scale (GBS) with 12 items had a two-factor structure. The first factor in the scale is about rejection/exclusion sub-dimension (e.g. "I feel like people do not care about me") and the second factor is about acceptance/inclusion sub-dimension (e.g. "I feel 1 connect with others"). Rejection/exclusion sub-dimension consists of totally 6 items and item factor loadings ranged between .67 and .84 . Acceptance/inclusion sub-dimension also consists of 6 items and item factor loadings ranged between .55 and .75 . Hair et al. (2010) considered factor loading values of .50 and over good. Hence, Item factor loadings are considered good. Communalities indicate the amount that each item explains the variance. Common factor variance values of items are recommended to be at least .30 and over (Pallant, 2011). Common factor variance values of the GBS items are observed between .31 and .72. The GBS items explained $52.24 \%$ of the total variance (Table 2). Thus, $32.80 \%$ of the total variance was explained by rejection/exclusion subscales, and $19.44 \%$ by acceptance/inclusion subscale.

Table 2. Factor Loadings, Communalities, Eigenvalues, and Explained Variance in the GBS

\begin{tabular}{llll}
\hline Item & $\begin{array}{l}\text { Rejection/ } \\
\text { Exclusion }\end{array}$ & $\begin{array}{l}\text { Acceptance/ } \\
\text { Inclusion }\end{array}$ & $\begin{array}{l}\text { Common Factor } \\
\text { Variance }\end{array}$ \\
\hline No & $\mathbf{. 8 4}$ & .08 & .72 \\
7 & $\mathbf{. 7 9}$ & .12 & .64 \\
12 & $\mathbf{. 7 9}$ & .11 & .63 \\
4 & $\mathbf{. 7 5}$ & .12 & .58 \\
6 & $\mathbf{. 6 7}$ & .02 & .46 \\
9 & $\mathbf{. 6 8}$ & .07 & .47 \\
11 & .06 & $\mathbf{. 5}$ & .56 \\
10 & .06 & $\mathbf{. 3}$ & .54 \\
5 & .13 & $\mathbf{. 6 8}$ & .48 \\
1 & .02 & $\mathbf{. 6 5}$ & .43 \\
2 & .20 & $\mathbf{. 6 6}$ & .47 \\
8 & .02 & $\mathbf{. 5 5}$ & \\
\hline Eigenvalue: & 3.94 & 2.33 & \\
Explained Variance: (Total: & $32.80 \%$ & $19.44 \%$ & \\
52.24\%) & & & \\
\hline
\end{tabular}

3.1.2 Confirmatory Factor Analysis Results

Table 3. Confirmatory Factor Analysis Fit Indices and Criteria Values of the General Belongingness Scale

\begin{tabular}{llll}
\hline Fit İndices & Perfect values & Acceptable values & Actual Values \\
\hline $\mathrm{p}^{\mathrm{a}}\left(\chi^{2}\right.$ test $)$ & $>.01$ or .05 & $<.01$ or .05 & 0.00 \\
$\chi^{2} / \mathrm{df}$ & $\leq 2$ & $2-5$ & $153.36 / 53=2.89$ \\
RMSEA & $\leq .05$ & $\leq .08$ & .06 \\
RMR & $\leq .05$ & $\leq .08$ & .04 \\
SRMR & $\leq .05$ & $\leq .08$ & .04 \\
GFI & $\geq .95$ & $\geq .90$ & .96 \\
AGFI & $\geq .95$ & $\geq .90$ & .94 \\
CFI & $\geq .95$ & $\geq .90$ & .97 \\
NFI & $\geq .95$ & $\geq .90$ & .96 \\
NNFI & $\geq .95$ & $\geq .90$ & .96 \\
\hline
\end{tabular}

CFA was conducted in order to determine whether the GBS structure was confirmed. Thus, fit indices obtained through CFA were reviewed and scale Chi-square value $\left(\chi^{2}=153.36, \mathrm{df}=53, \chi^{2} / \mathrm{df}=2.89, p<.001\right)$ was found significant. However, chi-square value is influenced by the sample size, and in a large sample size ignorable differences may seem significant due to large sample size. Hence, many fit criteria that are less affected by the sample size or eliminate the impact of sample size were developed (Tabachnick and Fidell, 2013). Fit indices for the GBS indicated good fit of the two structure model $(\mathrm{RMSEA}=.06, \mathrm{RMR}=.04, \mathrm{SRMR}=.04, \mathrm{GFI}=.96$, AGFI $=.94, \mathrm{CFI}=.97, \mathrm{NFI}=.96$, and $\mathrm{NNFI}=.96)$. In order to evaluate the fit indices obtained through CFA, fit criteria, often used in the literature, were 
reviewed (Çokluk, Şekercioğlu, and Büyüköztürk, 2010; Şimşek, 2007; Tabachnick and Fidell, 2013). Table 3 includes fit indices and criteria associated with CFA results of GBS.

Table 4 indicates the standardized factor loadings of the GBS between $\quad .45$ and $\quad .83$. All GBS items are at significant levels $(\mathrm{t}>2.576)$. Variance values that each item explained within the scale varied between .20 and .69 . Table 4 includes $t$ values obtained through CFA on the GBS, multiple correlation squares $\left(\mathrm{R}^{2}\right)$, composite reliability, and average variance extracted.

Table 4. T values obtained through CFA on GBS, multiple-correlation squares $\left(\mathrm{R}^{2}\right)$, factor loadings, composite reliability, and average variance extracted

\begin{tabular}{|c|c|c|c|c|c|c|}
\hline \multirow{2}{*}{ Factor and Items } & \multirow{2}{*}{$\mathrm{R}^{2}$} & & \multirow{2}{*}{ t value } & \multirow{2}{*}{$\begin{array}{l}\text { Composite } \\
\text { (CR) }\end{array}$} & \multirow[t]{2}{*}{ Reliability } & \multirow{2}{*}{$\begin{array}{l}\text { Average Variance } \\
\text { Extracted (AVE) }\end{array}$} \\
\hline & & & & & & \\
\hline \multicolumn{7}{|c|}{ Rejection/Exclusion } \\
\hline 3 & .69 & .83 & 22.86 & & & \\
\hline 7 & .55 & .74 & 19.52 & & & \\
\hline 12 & .51 & .72 & 18.55 & .85 & & $.64(64 \%)$ \\
\hline 4 & .51 & .71 & 18.51 & & & \\
\hline 6 & .32 & .57 & 13.75 & & & \\
\hline 9 & .34 & .58 & 14.25 & & & \\
\hline \multicolumn{7}{|c|}{ Acceptance/Inclusion } \\
\hline 11 & .47 & .69 & 16.33 & & & \\
\hline 10 & .46 & .68 & 16.16 & & & \\
\hline 5 & .39 & .62 & 14.55 & .77 & & $.46(46 \%)$ \\
\hline 1 & .28 & .53 & 11.98 & & & \\
\hline 2 & .34 & .59 & 13.53 & & & \\
\hline 8 & .20 & .45 & 9.97 & & & \\
\hline GBS Total & & & & .90 & & $.69(69 \%)$ \\
\hline
\end{tabular}

\subsection{Findings associated with Convergent Validity, Discriminant Validity, and Criterion Validity of the GBS}

Table 5. Pearson correlation coefficient values between the GBS subscales and the total score, the UCLA Loneliness Scale, the BMSLSS, and IPPA

\begin{tabular}{|c|c|c|c|c|c|c|c|c|c|c|c|c|c|c|}
\hline Variables & 1 & 2 & 3 & 4 & 5 & 6 & 7 & 8 & 9 & 10 & 11 & 12 & 13 & 14 \\
\hline $\begin{array}{l}1 . \\
\text { Acceptance/inclusion }\end{array}$ & --- & & & & & & & & & & & & & \\
\hline 2. Rejection/exclusion & $-.62^{* *}$ & --- & & & & & & & & & & & & \\
\hline $\begin{array}{l}3 . \quad \text { General } \\
\text { belongingness }\end{array}$ & $.90^{* *}$ & $-.90^{* *}$ & --- & & & & & & & & & & & \\
\hline 4. Loneliness & $-.52^{* *}$ & $.64^{* *}$ & $-.64^{* *}$ & --- & & & & & & & & & & \\
\hline 5. Life satisfaction & $.38^{* *}$ & $-.27^{* *}$ & $.36^{* *}$ & $-.49^{* *}$ & --- & & & & & & & & & \\
\hline 6. Mother trust & $.18^{*}$ & $-.23^{* * *}$ & $.23^{* *}$ & $-.31^{* *}$ & $.24^{* * *}$ & --- & & & & & & & & \\
\hline $\begin{array}{l}7 . \quad \text { Mother } \\
\text { communication }\end{array}$ & $.40^{* *}$ & $-.21^{*}$ & $.34^{* *}$ & $-.31^{* *}$ & $.49^{* *}$ & $.51^{* *}$ & --- & & & & & & & \\
\hline 8. Mother alienation & $.34^{* *}$ & $-.37^{* *}$ & $.39^{* *}$ & $-.48^{* *}$ & $.48^{* *}$ & $.48^{* *}$ & $.59^{* *}$ & --- & & & & & & \\
\hline 9. Father trust & $.19^{*}$ & $-.20^{*}$ & $.22^{*}$ & $-.25^{* *}$ & $.21^{*}$ & $.45^{* *}$ & $.32^{* * *}$ & $.49^{* *}$ & --- & & & & & \\
\hline $\begin{array}{l}10 . \quad \text { Father } \\
\text { communication }\end{array}$ & $.23^{* *}$ & -.16 & $.21^{*}$ & $-.19^{*}$ & $.41^{* *}$ & $.20^{*}$ & $.41^{* *}$ & $.43^{* *}$ & $.54^{* *}$ & --- & & & & \\
\hline 11. Father alienation & $.17^{*}$ & $-.28^{* *}$ & $.25^{* *}$ & $-.35^{* *}$ & $.48^{* *}$ & $.28^{* *}$ & $.31^{* *}$ & $.60^{* *}$ & $.33^{* *}$ & $.54^{* *}$ & --- & & & \\
\hline 12. Peer trust & $.31^{* *}$ & $-.28^{* *}$ & $.33^{* *}$ & $-.49^{* *}$ & $.39^{* *}$ & $.31^{* *}$ & $.35^{* *}$ & $.28^{* *}$ & $.21^{*}$ & .13 & .13 & --- & & \\
\hline $\begin{array}{ll}13 . & \text { Peer } \\
\text { communication } & \end{array}$ & $.36^{* *}$ & $-.34^{* *}$ & $.39^{* *}$ & $-.61^{* *}$ & $.50^{* *}$ & $.34^{* * *}$ & $.37^{* *}$ & $.38^{* *}$ & $.26^{* *}$ & $.19^{*}$ & $.28^{* *}$ & $.92^{* *}$ & --- & \\
\hline 14. Peer alienation & $.23^{* *}$ & $-.42^{* *}$ & $.36^{* *}$ & $-.64^{* *}$ & $.39^{* *}$ & $.28^{* *}$ & $.23^{* *}$ & $.46^{* *}$ & $.26^{* *}$ & .14 & $.47^{* *}$ & $.40^{* *}$ & $.58^{* *}$ & --- \\
\hline
\end{tabular}

Convergent validity is about evaluating the degree of relationship between measured two similar concepts. Discriminant 
validity, on the other hand, is about the degree of distinction between two conceptually similar structures. When evaluating the discriminant validity, the value of average variance extracted (AVE) is compared to the square of correlation between the two structures. If the AVE value is larger than the square of this correlation, discriminant validity can be provided (Hair et al., 2010). For the construct validity of the GBS, discriminant validity, and convergent validity, composite validity, calculated based on the structural equation model, and average variance extracted were calculated. Hair et al. (2010) states that values ranging between .50 and .60 are acceptable for composite reliability and values of .70 and above are considered good. It is seen that composite reliability values obtained for the GBS were very high. A value of .50 and above is recommended for the average variance extracted (Hair et al., 2010). Values of average variance extracted obtained for rejection/exclusion sub-dimension and overall scale can be considered on adequate levels; however, the value obtained for acceptance/exclusion seems to be a little below the critical value. The composite reliability for the GBS indicates that scale convergent validity was provided. Because squares of correlations for both subscales were smaller than the average variance extracted, it can be said that both subscales had separate structures, meaning that their discriminant validity was provided. As can be seen in Table 5, discriminant validity of both GBS subscales and the general belongingness total score with loneliness, life satisfaction, and parent and peer attachment variables was provided. Based on the data obtained from 140 students to examine the criterion validity for the GBS, correlation coefficients between the GBS and the UCLA Loneliness Scale, The Brief Multidimensional Students' Life Satisfaction Scale, and Inventory of Parent and Peer Attachment were computed and the results are given in Table 5.

As can be seen in Table 5, a high-level of negative relationship was found between the sub-dimension of acceptance/inclusion and the sub-dimension of rejection/exclusion and a high-level positive relationship was found between the general belongingness total score and those sub-dimensions. In addition, a high-level of negative relationship was found between rejection/exclusion and general belongingness total score and those sub-dimensions. A negative relationship between acceptance/inclusion sub-dimension and loneliness and a significant positive relationship with life satisfaction and parent and peer attachment variables were found. A positive relationship was found between rejection/exclusion sub-dimension and loneliness and a significant negative relationship with life satisfaction and parent and peer attachment variables were found. A negative relationship between general belongingness total score and loneliness was found and a significant positive relationship with life satisfaction and parent and peer attachment variables was found. Thus, criterion validity of the GBS was provided.

\subsection{Findings for the Reliability of the GBS}

For the reliability of the $G B S$, composite reliability values, average variance extracted, internal consistency coefficients, and test-retest reliability coefficients were calculated. For instance, Average Variance Extracted for acceptance/inclusion was found as .46 (46\%); for rejection/exclusion sub-dimension, it was .64 (64\%); and for the overall scale, AVE value was .69. Composite Reliability (CR) for the overall scale was found as .90.

The Cronbach's alpha coefficient, for the acceptance/inclusion sub-dimension was found as $\alpha=.76$; for rejection/exclusion sub-dimension, it was $\alpha=.85$; and for the scale overall, it was $\alpha=.81$. Hair et al. (2010) stated that Cronbach's alpha was required at least on the level of .70 and above for the reliability of scales. Test-retest reliability coefficient, obtained from the administration of the scale on 97 students with an interval of two weeks, was found as $\mathrm{r}=.80(p<.001)$. The value obtained through test-retest reliability coefficient, showed that the scale had high test-retest reliability (Büyüköztürk, 2008). In addition, acceptable levels of communality values of the GBS may be considered as another piece of proof.

\subsection{Scoring of General Belongingness Scale}

Items of the General Belongingness Scale are answered on a four-point likert-type scale with "(1) I never agree, (2) I somewhat agree, (3) I mostly agree, (4) I strongly agree". Items 3-4-6-7-9-12 in the scale were scored reverse six items added in to the scale made up the rejection/exclusion score; 6 items added in the scale made up the acceptance/inclusion score; and 12 items added in the scale made up the general belongingness score. Based on this, the increase in adolescents' general belongingness scores must mean high general belongingness levels for them.

\section{Discussion}

In the current research, the adaptation study of the General Belongingness Scale, developed by Malone et al. (2012) in order to measure individuals' general belongingness level, into Turkish language was conducted on adolescents. Exploratory factor analysis and confirmatory factor analysis were used to determine the construct validity of the scale. To evidence the criterion validity of the scale, correlation coefficients between the scale and parent and peers attachment, loneliness, and life satisfaction were examined. Exploratory factor analysis showed that the scale had a two-dimensional structure as in the original form. Confirmatory factor analysis, conducted to check whether the present structure of the scale was confirmed for Turkish culture, indicated that the model was suitable and fit indices were very good. Factor analyses findings and criterion validity findings showed that the scale validity was in acceptable levels. In 
addition, the convergent validity and discriminant validity were provided.

Composite reliability coefficients and internal consistency values along with test-retest values computed for the reliability showed that the GBS was a reliable instrument to determine Turkish adolescents' general belongingness levels. In another research, Yildiz (2016a) conducted an adaptation study of the GBS into Turkish language for young adults and factor loadings through configural invariance were found to be .37 and .72 . Other psychometric features of the GBS were also examined in the same research and strict invariance between male and female participants was provided.

In the current study, lack of translation back into English language following the translation of scale into Turkish language may be considered a limitation of the research. Another limitation may be about the participants from one city and region. In addition, it is not known whether adolescent participants had any clinical problems. The findings of the current research must be considered taking those limitations into account. For further studies, investigating psychometric features the GBS based on data to be collected in different cities and regions may be recommended. GBS can be used to define the relation between the general belongings of Turkish adolescents and variables such as their self-esteem, perceived social support, life satisfaction, bullying and depression by other researchers who want to study it.

To sum up, in the current research conducted in order to adapt the General Belongingness Scale into Turkish language for adolescents, the results of reliability and validity analyses indicated that the current scale can be safely used in further studies with Turkish adolescents.

\section{References}

Allen, K. A., \& Bowles, T. (2012). Belonging as a guiding principle in the education of adolescents. Australian Journal of Educational \& Developmental Psychology, 12, 108-119.

Armsden, G. C., \& Greenberg, M. T. (1987). The inventory of parent and peer attachment: Individual differences and their relationship to psychological well-being in adolescence. Journal of Youth and Adolescence, 16, 427-451. https://doi.org/10.1007/BF02202939

Baskin, T. W., Wampold, B. E., Quintana, S. M., \& Enright, R. D. (2010). Belongingness as a protective factor against loneliness and potential depression in a multicultural middle school. The Counseling Psychologist, 38(5), 626-651. https://doi.org/10.1177/0011000009358459

Baumeister, R. F., \& Leary, M. R. (1995). The need to belong: Desire for interpersonal attachments as a fundamental human motivation. Psychological Bulletin, 117(3), 497-529. https://doi.org/10.1037/0033-2909.117.3.497

Baumeister, R. F., \& Tice, D. M. (1990). Point-counterpoints: Anxiety and social exclusion. Journal of Social and Clinical Psychology, 9(2), 165-195. https://doi.org/10.1521/jscp.1990.9.2.165

Brown, T. A. (2006). Confirmatory factor analysis for applied research. New York \& London: The Guilford Press.

Büyüköztürk, Ş. (2008). Handbook of data analysis for social sciences. (9. Basım). Ankara: Pegem Akademi Yayıncılık.

Chen, W. C. (2003). Adolescent interpersonal relationship quantity and quality, belongingness, and loneliness. Unpublished Doctoral Thesis, The Department of Educational Psychology, The University of Texas at Austin, Texas.

Choenarom, C., Williams, R. A., \& Hagerty, B. M. (2005). The role of sense of belonging and social support on stress and depression in individuals with depression. Archives of Psychiatric Nursing, 19(1), 18-29. https://doi.org/10.1016/j.apnu.2004.11.003

Çokluk, Ö., Şekercioğlu, G., \& Büyüköztürk, Ş. (2010). Multivariate statistics for the social sciences. SPSS and LISREL applications. (1.Basım). Ankara: Pegem Akademi Yayınc1lık.

Demir, A. (1989). Reliability and validity of the UCLA Loneliness Scale. Türk Psikoloji Dergisi, 7(23), 14-18.

Hagerty, B. M., \& Williams, R. A. (2010). The effects of sense of belonging, social support, conflict, and loneliness on depression. Nursing Research, 48(4), 215-219. https://doi.org/10.1097/00006199-199907000-00004

Hagerty, B. M., Lynch-Sauer, J., Patusky, K. L., Bouwsema, M., \& Collier, P. (1992). Sense of belonging: A vital mental health concept. Archives of Psychiatric Nursing, 6(3), 172-177. https://doi.org/10.1016/0883-9417(92)90028-H

Hair, Jr, J. F., Black, W. C., Babin, B. J., \& Anderson, R. E. (2010). Multivariate data analysis (7th ed.). New Jersey: Pearson Prentice Hall.

Hox, J. J. (1995). Amos, Eqs and Lisrel for Windows: A comparative review. Structural Equation Modeling, 2(1), 79-91. https://doi.org/10.1080/10705519509539996

Kocayörük, E. (2010). A Turkish adaptation of the inventory of parent and peer attachment: The reliability and validity 
study. Eurasian Journal of Educational Research, 40, 131-153.

Malone, G. P., Pillow, D. R., \& Osman, A. (2012). The general belongingness scale (GBS): Assessing achieved belongingness. Personality and Individual Differences, 52, 311-316. https://doi.org/10.1016/j.paid.2011.10.027

Mellor, D., Stokes, M., Firth, L., Hayash, Y., \& Cummins, R. (2008). Need for belonging, relationship satisfaction, loneliness, and life satisfaction. Personality and Individual Differences, 45(3), $213-218$. https://doi.org/10.1016/j.paid.2008.03.020

O'Rourke, J., \& Cooper, M. (2010). Lucky to be happy: A study of happiness in Australian primary students. Australian Journal of Educational \& Developmental Psychology, 10, 94-107.

Pallant, J. (2011). SPSS Survival Manual A step by step guide to data analysis using SPSS (4th ed.). Australia: Allen \& Unwin.

Russell, D., Peplau, L. A., \& Cutrona, C.E. (1980). The revised UCLA Loneliness Scale: Concurrent and discriminant validity evidence. Journal of Personality and Social Psychology, 39, 472-480. https://doi.org/10.1037/0022-3514.39.3.472

Russell, D., Peplau, L. A., \& Ferguson, M. L. (1978). Developing a measure of loneliness. Journal of Personality Assessment, 42, 290-294. https://doi.org/10.1207/s15327752jpa4203_11

Şeker, H., \& Gençdoğan, B. (2006). eveloping measurement tools in psychology and education. (1.Basım). Ankara: Nobel Yayın Dağıtım.

Seligson, J. L., Huebner, E. S., \& Valois, R. F. (2003). Preliminary validation of the brief multidimensional students' life satisfaction scale (BMSLSS). Social Indicators Research, 61, 121-145. https://doi.org/10.1023/A:1021326822957

Şimşek, Ö. F. (2007). Introduction to structural equation modeling: Basic principles and LISREL applications. Ankara: Ekinoks Yayınları.

Siyez, D. M., \& Kaya, A. (2008). Psychometric properties of the Turkish version of the brief multidimensional students' life satisfaction scale (BMSLSS). Journal of Psycho educational Assessment, 26, 139-147. https://doi.org/10.1177/0734282907307802

Tabachnick, B. G., \& Fidell, L. S. (2013). Using multivariate statistics (6th ed.). New York: Allyn and Bacon.

Yildı, M. A. (2013, September). Adaptation of the General Belongingness Scale (GBS) to Turkish: Validity and reliability studies. Report presented at İstanbul 2013 World Congress of Psychological Counseling and Guidance, Boğaziçi Üniversitesi, İstanbul.

Y1ldı, M. A. (2016). Serial multiple mediation of general belongingness and life satisfaction in the relationship between attachment and loneliness in adolescents. Educational Sciences: Theory \& Practice, 16(2), 553-578. https://doi.org/10.12738/estp.2016.2.0380

Y1ldiz, M. A. (2016a). On measurement equivalence and gender-based examination of measurement equivalence for General Belongingness Scale (GBS) in young adults. Uşak Üniversitesi Sosyal Bilimler Dergisi, 9(2), 50-72.

\section{Copyrights}

Copyright for this article is retained by the author(s), with first publication rights granted to the journal.

This is an open-access article distributed under the terms and conditions of the Creative Commons Attribution license which permits unrestricted use, distribution, and reproduction in any medium, provided the original work is properly cited. 